\title{
RECONOCIMIENTO, TOLERANCIA E INTERCULTURALIDAD. LA AGENDA PENDIENTE DE UN MUNDO DE EXTRAÑOS MORALES
}

\begin{abstract}
Raúl Villarroel ${ }^{1}$
Resumen: Se analizan las complejidades de un fenómeno de interés actual como es el de la inevitable y cada vez más creciente situación de forzada coexistencia entre extraños morales, hecho desencadenado por el derrumbe de las determinaciones que antańo restringían territorialmente la vida de los sujetos al interior de espacios nacionales delimitados. Por diversas razones, esos mismos sujetos, se ven hoy forzados a migrar y vincularse en nuevos espacios geográficos comunes, donde deben enfrentar sus diferencias, sin contar con las habilidades sociales que les permitirían interactuar coordinando planes de acción, al margen de escenas conflictivas, o libres de prejuicios xenófobos e intolerancia. A partir de lo anterior, se busca encontrar un correlato empírico a lo señalado y pensar los problemas del reconocimiento, la tolerancia y la interculturalidad en una escena social cercana a nuestra propia experiencia nacional. El tema del reconocimiento cobra especial significación cuando de lo que se trata es de evaluar su expresión en relación con diferencias culturales profundas entre individuos que comparten un espacio vital e histórico, como podría pensarse que corresponde hacer con los problemas suscitados a partir de las demandas de reconocimiento planteadas por el pueblo mapuche al Estado de Chile.
\end{abstract}

Palabras clave: reconocimiento, interculturalidad, tolerancia, mapuche, Honneth

\section{Recognition, Tolerance and Interculturality. A pending affair in a world of moral strangers}

\begin{abstract}
The complexities of a current interest phenomenon such the unavoidable and increasing situation of coexistence between moral strangers, understood as a fact triggered by the collapse of historical territorial restrictions imposed to the life of people inside national limits, is examined in this paper. Many of these individuals are now forced to migrate and coexist in new geographical spaces, where they must face their differences, without the social skills that would allow them to interact by coordinating action plans, regardless of conflicting dimensions, or freed from xenophobic prejudice and intolerance. This paper seeks to find an empirical correlate to this argument and meditate about the problems of recognition, tolerance and interculturality in a social scene, close to our own national experience. The subject of recognition is referred to those deep cultural differences that could emerge between individuals who are compelled to share a new vital and biographical space. This will be analyzed in correspondence to the problems arising from the demands of recognition raised today by the Mapuche people to the chilean State.
\end{abstract}

Key words: recognition, interculturality, tolerance, mapuche, Honneth

\section{Reconhecimento, Tolerância e Interculturalidade. A agenda pendente de um mundo de estranhos morais}

Resumo: Analisam-se as complexidades de um fenômeno de interesse atual, como é a inevitável e cada vez mais crescente situação de convivência forçada entre estranhos morais, feito desencadeado pelo colapso das determinaçóes que antigamente restringiam territorialmente a vida dos sujeitos ao interior de espaços nacionais delimitados. Por diversar razóes, esses mesmos sujeitos, se vêm hoje forçados a migrar e se envolver em novos espaços geográficos comuns, onde devem enfrentam as suas diferenças, sem contar as habilidades sociais que lhes permitiriam interagir coordenando planos de ação, para além cenas conflitivas, ou livres de preconceitos xenófobos e intolerância. A partir disso, busca-se encontrar uma correlação empírica para o assinalado e pensar os problemas do reconhecimento, da tolerância e da interculturalidade em uma cena social que está próxima à nossa própria experiência nacional. A questão do reconhecimento assume especial importância, quando o que está em questáo é avaliar a sua expressáo em relaçáo às diferenças culturais profundas entre indivíduos que compartilham um espaço vital e histórico, como se poderia pensar que isso é feito com os problemas decorrentes das demandas de reconhecimento propostas pelo povo mapuche ao Estado do Chile.

Palavras-chave: reconhecimento, interculturalidade, tolerância, mapuche, Honneth

\footnotetext{
${ }^{1}$ Departamento de Filosofía, Facultad de Filosofía y Humanidades, Universidad de Chile, Chile Correspondencia: rvillarr@uchile.cl
} 
Se podría afirmar con facilidad que la convivencia humana es una escena de conflicto inevitable y, sobre todo, permanente. O, en el mejor de los casos, un estado transitorio entre un conflicto ya resuelto y la inminente ocurrencia de otro nuevo. Aunque, como sabemos, el orden social depende del modo en que los actores coordinen sus acciones. Por lo que es menester tener en cuenta que - tal como ha sostenido Jürgen Habermas- los actores sociales pueden coordinar de diversos modos sus interacciones, sea propiciando o evitando el desencadenamiento de conflictos(1).

La primera mirada, de la interacción como posibilidad de conflicto, nos hace pensar que, al menos en principio, resultaría posible sostener expectativas para la resolución de los enfrentamientos sociales, dependiendo de que los actores buscaran una mutua comprensión y aceptación de sus diferencias; es decir, que actuaran de modo consensual y comunicativo. No intentando hacer prevalecer solo sus prerrogativas individuales, o corporativas, en desmedro de las pretensiones ajenas, recurriendo al empleo de cualquier tipo de dispositivos estratégicos e instrumentales para la satisfacción de sus intereses puramente egoís$\operatorname{tas}(1)$.

De tal modo, la cualidad de la convivencia social no debiera medirse únicamente por los logros individuales o solo por la distribución equitativa o justa de los bienes a la que los individuos pudieran tener acceso, como habitualmente tendemos a creer que debiera ser, sino más bien debiera estar esencialmente vinculada a ciertas concepciones respecto de cómo y cuánto los sujetos establecen un "reconocimiento" recíproco entre ellos. En el caso de la convivencia entre individuos provenientes de esquemas culturales e identitarios disímiles esto es aún más relevante.

Un mundo asediado por el virus de la intolerancia y plagado de aberrantes expresiones de xenofobia ocupa un lugar preponderante en el universo noticioso de nuestros días. Sabemos bien que esta es la experiencia más relevante y a la vez problemática que se puede constatar como expresión del fenómeno de la globalización en curso en el planeta.
Ello nos pone de cara a las complejidades de otro fenómeno de interés actual, el de la inevitable y cada vez más creciente situación de forzada coexistencia entre extraños morales, desencadenado fundamentalmente, aunque no de manera exclusiva, por el derrumbe de las determinaciones que antaño restringían territorialmente la vida de los sujetos al interior de espacios nacionales bien delimitados. Por diversas y muy conocidas razones, esos mismos sujetos se ven hoy forzados a migrar y estrechar vínculos en nuevos espacios geográficos que les resultan comunes, donde deben enfrentar sus diferencias de origen, pero sin contar con las efectivas garantías jurídicas ni con las habilidades sociales que les permitirían interactuar coordinando planes de acción conjunta, al margen de escenas conflictivas de cualquier tipo, o libres de prejuicios xenófobos e intolerancia.

Sustentado en la noción de "interculturalidad", ha emergido durante las últimas décadas un modelo teórico y explicativo que busca establecer una comprensión ajustada a los problemas característicos de la sociedad global $(2,3)$, en el que tiende a plantearse la necesidad de disolver cada vez más las referencias distintivas que hasta hace muy poco permitían diferenciar e incluso contraponer frontalmente a los sujetos en relación con su origen nacional, sus identidades lingüísticas, sus confesiones religiosas, sus condiciones económicas o sus definiciones políticas. Tal interculturalidad, entendida de modo simple como el proceso sociocultural mediante el cual se interpenetran e integran más o menos conflictiva o cooperativamente las diversas culturas, constituye un desafío de gran envergadura para el futuro de la humanidad, puesto que, de no avizorarse expectativas de resolución de la conflictividad inherente a la coexistencia obligada de individuos heterogéneos en cuanto a sus identidades culturales, la amenaza de un incremento exponencial de la violencia y la descomposición del orden social se hace cada vez más inminente. El paradigma intercultural se yergue así como el muro de contención que detiene el avance de semejante y previsible cataclismo humano, en el que la cara más fea de la violencia fratricida nos resulta aún enteramente desconocida.

En relación con lo anterior, el filósofo alemán Otfried Höffe recientemente se ha preguntado por el modo en que individuos de diferentes culturas y 
religiones pueden llegar a vivir juntos en comunidad(4:132). Pese a todo lo que pudiera argumentarse en contrario, duda de que la posibilidad de una convivencia exitosa entre diversas manifestaciones culturales esté necesariamente ligada a las referencias normativas establecidas por la forma constitucional de la democracia(4:132). Serían otros tres factores los gravitantes, a su juicio. Y lo serían porque, facilitando el discurso intercultural, no están ligados a la constitución de la democracia, que establece que todo procede del pueblo. Höffe los describe así: "El primer factor consiste en el Estado de derecho, el cual considera a todas las personas como iguales ante la ley. El segundo factor se refiere al Estado constitucional, el cual se relaciona, a su vez, con el Estado de derecho liberal. Este obliga a la legislación a ajustarse a los derechos humanos, de modo tal que nadie pueda ser discriminado o privilegiado debido a su raza, sus creencias o su religión. [El] tercer factor [...] consiste en la tolerancia, aunque también puede ser llamado liberalidad [...]"(4:132.). Se destaca en este caso el valor fundamental de la tolerancia, que "entendida como principio jurídico y estatal, eleva la libertad religiosa y de opinión al rango de un derecho humano fundamental" (4:133).

Höffe piensa que a una comunidad tolerante le sucede una sociedad también tolerante, lo que permite que cada ciudadano pueda adherir a lo que le parezca, como también a nada, si no le parece. Finalmente, esto equivalente a decir que "un ciudadano tolerante muestra respeto también a las personas que profesan otras religiones, confesiones o convicciones políticas, o que persiguen otros planes de vida" (4:133). De este modo, la tolerancia se convierte en una "virtud ciudadana”, o sea, algo mucho más decisivo que la simple capacidad de resistir "los males y los dolores, los tormentos o los golpes del destino" (4:133), que es como a menudo se le entendió antes de la emergencia arrolladora del paradigma sociomoral actual de la interculturalidad.

En este caso — volviendo a Höffe-, se trata de soportar, pero no de soportar estoicamente experiencias dolorosas, sino de soportar al extranjero, al Otro diferente, al que tiene otras creencias y costumbres, al que históricamente se le ha negado, menospreciado o desconocido (para los griegos antiguos fue el "bárbaro"). En este sentido, es po- sible pensar particularmente en aquellos peligros que se presentan en todo lugar en que se enfrentan dos culturas diversas. Como señala el filósofo alemán, está el riesgo de que prevalezca un "imperialismo cultural", que busque ya sea desplazar o eliminar a las otras culturas diferentes; o el riesgo del "relativismo cultural", que hace caso omiso de las diferencias intrínsecas entre las culturas y otorga idéntico valor a cualquier manifestación, incluso importando valores contradictorios entre sí(2:273). En todo ello está implicado, por cierto, un ineludible problema de reconocimiento.

Podría decirse entonces que la interculturalidad es ese proceso en el que personas diversas o grupos heterogéneos se comunican e interactúan recíprocamente en condiciones de simetría moral, lo que permite a sujetos diversos por su origen mirarse mutuamente, a la luz de valores capaces de hacer aparecer las características del otro como valiosas para una praxis común; evitando deliberadamente que estrategias manifiestas o encubiertas de dominación, supremacía o hegemonía conduzcan hacia intereses individuales y egoístas los destinos de su relación. A veces se ha querido homologar a una estructura textil a la interculturalidad; en tanto está constituida por diferentes hilos que, entretejidos, componen esa trama que no podría obtenerse a partir de uno solo de ellos.

Pero, como se acaba de decir, esto alude directa o indirectamente al asunto del reconocimiento y a las formas constitutivas de desprecio o menosprecio que han sido identificadas en la historia entera de la filosofía, aunque parezca haberse hecho presente de modo más visible en el pensamiento moderno, desde Hegel en adelante, para ser luego retomada y llevada a su más fecunda expresión en nuestro tiempo por pensadores como Axel Honneth, Charles Taylor o Paul Ricoeur, que lo han convertido en un asunto central de sus particulares reflexiones. Este último, en la Introducción de su obra Caminos del reconocimiento, publicada originalmente en 2004, distingue tres enfoques filosóficos relativos al asunto del reconocimiento, que en apariencia no tendrían vinculación común y que son: "El de sentido kantiano, llamado $R e$ kognition en la primera edición de la Crítica de la razón pura. El bergsoniano, con el nombre de 'el reconocimiento de los recuerdos'. Finalmente, el hegeliano, hoy en plena expansión, con el nom- 
bre de Anerkennung, que data de la época de la Realphilosophie de Hegel en Jena"(5:32).

De hecho, Axel Honneth afirma que el concepto de "reconocimiento", entendido en este último sentido (Anerkennung), en cualquiera de sus versiones, ha jugado siempre un papel esencial dentro de la filosofía práctica(6). En la ética antigua — sostiene el pensador alemán- existía la convicción de que solo podía llevar una vida buena aquella persona cuyo modo de actuar pudiera encontrar estimación social dentro de la polis. Por su parte, agrega Honneth, la filosofía moral escocesa confiaba en que el reconocimiento o la desaprobación públicos constituían el mecanismo social mediante el cual el individuo se veía impulsado a alcanzar las virtudes deseables. En Kant, finalmente, el respeto (Achtung) cumple la función de principio supremo de la moral, en cuanto contiene el núcleo del imperativo categórico que conmina a tratar a todo ser humano como un fin en sí mismo. Aunque, con excepción de Hegel naturalmente, que en este sentido habría sido un antecedente aislado, ninguno de los autores clásicos llegó a convertir el principio de reconocimiento como tal en la piedra angular de una ética, por mucho significado indirecto que le hayan atribuido. Este concepto permaneció siempre a la sombra de otras determinaciones consideradas más fundamentales(7).

En los últimos veinte años aproximadamente ha surgido toda una serie de debates políticos y movimientos sociales que han propiciado una consideración más vigorosa de la idea de reconocimiento. En variados discursos emergentes de las últimas décadas, sea en las discusiones sobre multiculturalismo, interculturalidad, o en la autocomprensión teórica del feminismo(8), se revela rápidamente al modo de un paradigma común la representación normativa que concibe la idea de que los individuos o los grupos sociales tienen que encontrar reconocimiento o respeto en su "diferencia" (9). Por cierto, el esfuerzo que hoy se despliega para delimitar y aislar sistemáticamente la equivocidad inherente al concepto define la discusión actual en torno a una moral sustentada en el reconocimiento, cuya multiplicidad significativa constituye toda una dificultad que no podemos abordar en estas páginas, por lo cual simplemente nos limitamos a mantener a la vista la apropiación que hace el mismo Axel Honneth de la tipología del reconocimiento del joven Hegel, ya que en estos escritos tempranos del periodo de Jena aparece la propuesta de tres modelos diversos de reconocimiento(10), que serían — dicho muy latamente- los de amor, respeto y solidaridad.

En consonancia con este campo semántico general de comprensión de la noción de reconocimiento, los autores finlandeses Rauno Huttunen y Hannu L. T. Heikkinen(11), por ejemplo, destacan la importancia de la construcción y existencia de un "círculo positivo de reconocimiento". Este dar y recibir reconocimiento es conceptualizado por los autores como "dialéctica del reconocimiento" y trasunta en un mecanismo social central y fundamental para hablar de interculturalidad, puesto que constituye un encuentro y una interacción cultural que se va tejiendo como un proceso recíproco, de carácter igualitario, de sus protagonistas con sus respectivos mundos culturales. El reconocimiento recíproco "establece un fuerte sentido de solidaridad"(11), lo que permite a sus integrantes sentirse importantes y respetados en la comunidad. En efecto, posibilita que los espacios sociales se desplieguen en virtud de su carácter de comunidad; es decir, como "comunidad de reconocimiento recíproco", en la que, a modo de efecto derivado, se potencian los logros individuales. Cuando los integrantes de una comunidad "se respetan mutuamente como personas y aprecian las habilidades y capacidades de cada uno" se puede hablar de respeto de las identidades individuales y de los mundos culturales en que tales identidades se han construido ${ }^{2}$. Precisando, tales relaciones sociales "son siempre relaciones de solidaridad: en ellas brindo al otro más que respeto o tolerancia, al saber que mis metas de vida son facilitadas o enriquecidas por sus capacidades"(6:297). Así, la autorrealización de los individuos dependerá de la condición previa de la existencia de una comunidad de pertenencia, en la que los sujetos se estimen de modo recíproco conforme a fines compartidos(6:297).

Atendiendo a ello, habría entonces un corto paso que separa de la comprensión ya universalizada de que la cualidad moral de las relaciones sociales no solo tiene que medirse, como ya se dijo, por la

\footnotetext{
${ }^{2}$ Agradezco en relación con este pasaje del texto, las ideas y las referencias aportadas por la Prof. Gricelda Figueroa Irarrázabal.
} 
autorrealización individual que cada uno es capaz de conseguir en el lapso de una vida -incluso independientemente del concurso de los otros seres humanos con quienes debe compartiro por una distribución equitativa o justa de los bienes materiales; sino que, más bien, debe estar esencialmente vinculada a ciertas concepciones respecto de cómo y en cuanto qué se reconocen mutua y particularmente los sujetos, en sus derechos, identidades, diversidades y cultura.

Así, entonces, a partir de planteamientos políticos va resultando gradual y paulatinamente una discusión de filosofía moral, cuyo punto de partida está determinado por una reflexión que entiende el contenido normativo de la moral como susceptible de ser explicado a partir de determinadas formas de reconocimiento recíproco, que es lo queda implicado cuando se habla del "moral point of view" ${ }^{\prime 3}$, en referencia a aquellas cualidades deseables o reprobables de las relaciones que los sujetos mantienen entre ellos.

Vale la pena detenerse un momento en este punto para hacer unas últimas consideraciones, intentando encontrar un cierto correlato empírico a lo hasta aquí señalado y pensar los problemas del reconocimiento, la tolerancia y la interculturalidad en una escena social cercana y visible a nuestra propia experiencia. Ello porque el tema del reconocimiento cobra especial significación cuando se trata de evaluar su expresión en relación con diferencias culturales profundas entre individuos que comparten un espacio vital e histórico común, como podría pensarse que corresponde hacer con los problemas suscitados a partir de las demandas de reconocimiento planteadas por el pueblo mapuche al Estado de Chile. Ello constituye una situación que puede ser calificada de ejemplar en el sentido mencionado, porque nos permite constatar la existencia, o inexistencia, de una conciencia intercultural en el país; como asimismo la disposición favorable, o desfavorable, hacia ese reconocimiento recíproco con que tendrían que medirse expresiones culturales heterogéneas (las chilena y mapuche); más aun cuando ellas están determinadas por una coexistencia territorial que

\footnotetext{
${ }^{3}$ Se usa aquí la expresión en su acepción filosófica habitual, para describir aquellas condiciones específicas de la moralidad, por cuya determinación es posible trascender a la fuerza imperativa de los contextos particulares y alcanzar la perspectiva de la universalidad.
}

en este caso puede entenderse como ineludible.

Ciertamente, parece difícil admitir que ese respeto o esa integración —anodina y puramente formal- de los que es objeto el ciudadano mapuche — si atendemos para ello a la condición de persona jurídica y a las garantías cívicas de las que teóricamente dispone según el ordenamiento normativo vigente- constituya expresión de un auténtico y cabal reconocimiento suyo, de una aceptación equitativa de su particularidad cultural y una integral consideración de su diferencia humana específica. Más bien resultaría fácil pensar que la condición social, cultural, económica y política de la comunidad mapuche está hoy - y lo ha estado por siglos - fuertemente determinada por precarias expresiones de reconocimiento provenientes de la sociedad chilena y también por experiencias de severa discriminación, que no pueden sino ser comprendidas en términos de lo que Honneth ha definido como formas de desprecio (Missachtung), constituidas por el maltrato, que afecta su integridad física; la exclusión, que afecta su integridad social, y la humillación, que afecta su honor y su dignidad(12).

De tal manera, las señales de resistencia frente al Estado y al orden constitucional que identifican a lo que algunos denominan la "causa mapuche" en nuestros días(13), que por lo visto canalizan profundos sentimientos de injusticia y humillación derivados del maltrato y la exclusión de la que el mapuche expresa haber sido objeto, tendrían que entenderse como la expresión inequívoca de una inevitable reacción frente a un modo en verdad fallido del reconocimiento; que no es tal reconocimiento, porque en su pura formalidad legal - a veces hipócrita y vacía - invisibiliza al sujeto de su acción y hace caso omiso de su identidad cultural específica, homologándolo al resto de los miembros de la sociedad chilena u otorgándole derechos formales que difícilmente va a poder ejercer a cabalidad, dadas las indesmentibles desventajas y limitaciones de su condición social. El reclamo correspondería, sin duda, a lo que Höffe califica como el "segundo nivel de universalidad" de los derechos, es decir, el de la validez intercultural y atemporal, aludiendo con ello al hecho de que incluso quienes viven fuera de la cultura jurídica occidental y de su contemporaneidad debería poseer determinados derechos(14:17). 
Ahora bien, así entendidas las cosas, se podría afirmar — siguiendo a Honneth en esto nuevamente- que son los "sentimientos de desprecio" y las "experiencias de injusticia" de los despreciados (la gente mapuche, para el caso) los que impulsan a la resistencia y al conflicto(6:27). Así ocurre en la mayor parte de los conflictos sociales de nuestro tiempo. Son las demandas de reconocimiento instatisfechas las que los desencadenan finalmente. Lo paradójico es que no son sino los mismos presupuestos de reconocimiento social que dan forma al orden sociomoral de las sociedades actuales, entre ellas la chilena, los que - como dice Honneth(6:36) — "poseen por fuerza de sus [propios] principios implícitos un excedente de validez (Geltungsüberhang), que puede ser exigido por los afectados en contra de las relaciones de reconocimiento fácticas" e insuficientes con las que se pretende dar por terminada una tarea que se encuentra históricamente suspendida e inconclusa, y merece mayor atención de la que hasta ahora se le ha prestado. Porque "lo que procura como fuerza moral los desarrollos y progresos en el interior de la realidad de vida social del ser humano es la lucha por el reconocimiento"(6:227).

De tal modo, resulta posible pensar que esta sería la causa fundamental que motiva a los individuos o grupos sociales a cuestionar el orden prevaleciente - como en el caso del conflicto mapuche en nuestro país-, y a manifestarse de manera resistente frente al Estado y el orden constitucional, asistidos por la convicción moral de que, "en relación con su situación o particularidad, los principios de 'reconocimientos legítimos' se aplican de manera incorrecta o inadecuada” (15:140).

En definitiva, el reconocimiento de los pueblos originarios constituye un punto ciego para nuestro presente histórico, forma parte de esa agenda pendiente de la sociedad chilena, un gigantesco desafío que la interpela en razón de sus propios principios constitutivos, supuestamente democráticos e igualitarios.

Para concluir, y pensando en una de las múltiples expresiones en las que podría canalizarse una respuesta a esa ineludible interpelación, podemos coincidir con lo propuesto por la investigadora mapuche Elisa Loncón cuando afirma que: "Una educación intercultural inclusiva para todos los chilenos conducirá a que las nuevas generaciones conozcan y valoren las culturas originarias. Esto permitirá vencer los prejuicios, los miedos, los estigmas que por años han cautivado principalmente a la prensa, a la escuela, a la sociedad, sobre los indígenas como flojos, violentos, borrachos. Chile necesita valorar y querer a sus pueblos indígenas y para que ello ocurra, primero debe conocerlos, aprender de su historia, cosmovisión, valores, conocimientos; no se puede valorar lo que no se conoce, ni menos querer lo que se desconoce. La diversidad exige un cambio de paradigma y de diálogo epistemológico con las culturas originarias. Este es el gran desafío de la educación y de las universidades en particular" (16).

\section{Agradecimientos}

Resultado de la participación de su autor en calidad de Investigador Titular en el Proyecto Anillos SOC 1110 de CONICYT "Iluminando un dilema educacional en la complejidad de un mundo multicultural. Fortaleciendo la formación en Ética e Interculturalidad en estudiantes universitarios/as y profesionales" 2013-2015. 


\section{Referencias}

1. Habermas J. Conciencia moral y acción comunicativa. Paidós: Barcelona; 1985.

2. Höffe O. La tolerancia en tiempos de conflictos interculturales. En Höffe O. El proyecto politico de la Modernidad, México D.F.: FCE; 2008: 267-294.

3. Alcina M. La comunicación intercultural. Barcelona: Anthropos; 2003.

4. Höffe O. La tolerancia en tiempos de conflictos interculturales. Reflexiones de un filósofo político. Areté (Revista de Filosofía) 2010; XXII(1): 131-146.

5. Ricoeur P. Caminos del Reconocimiento. Tres estudios. México: FCE; 2006.

6. Honneth A. Critica del agravio moral. Patologías de la sociedad contemporánea. México: FCE; 2009.

7. Honneth A. Entre Aristóteles y Kant. Esbozo de una moral del reconocimiento. Logos (Anales del Seminario de Metafísica) 1998; 1: 17-37.

8. Hirschmann N. Freedom, Recognition and Obligation: A Feminist Approach to Political Theory. American Political Science Review 1989; 83(4): 1227.

9. Taylor Ch. Multiculturalismo y politica del reconocimiento. México: FCE; 2010.

10. Honneth A. El reconocimiento como ideología. Isegoría 2006; 35: 129-150.

11. Huttunen R, Heikkinen HLT. Teaching and the dialectic of recognition. Pedagogy, Culture \& Society 2004; 12(2): 163 174, DOI: $10.1080 / 14681360400200194$.

12. Honneth A. La lucha por el reconocimiento. Por una gramática moral de los conflictos sociales. Barcelona: Crítica; 1997.

13. Aylwin J. Causa mapuche: La herida de Chile. ACCIÓN. Asociación Chilena de Organizaciones No Gubernamentales; 2010. Disponible en http://accionag.cl/opinion/causa-mapuche-la-herida-de-chile/. Consultado el 02.05.15.

14. Höffe O. Intercambio transcendental: ¿Un modelo de legitimación para los Derechos Humanos? Universitas Philosophica $2011 ; 28(57): 15-36$.

15. Araya J. Una interpretación del conflicto Mapuche y el reconocimiento desde la perspectiva de Axel Honneth: Una concepción moral y ética. Revista Chilena de Derecho y Ciencia Politica 2012; 3(1): 131-146.

16. Loncón E. Educación intercultural para todos. Red por los Derechos Educativos y Lingüísticos de los Pueblos Indígenas de Chile; 2013. Disponible en http://redeibchile.blogspot.com/2013/01/educacion-intercultural-para-todos.html Consultado el 20.03.15.

Recibido: 10 de mayo de 2015

Aceptado: 15 de julio de 2015 